\title{
Glicerina na alimentação de cordeiros terminados em confinamento: características quantitativas da carcaça e qualitativas da carne
}

\author{
[Glycerin in feeding of lambs finished in feedlot: quantitative characteristics \\ of carcass and qualitative characteristics of meat] \\ E.M.O. D'Aurea, J.M.B. Ezequiel, V.C. Santos, A.P. D'Aurea, V.B. Carvalho, \\ M.T.C. Almeida, H.L. Perez \\ Faculdade de Ciências Agrárias e Veterinárias - FCAV - Unesp - Jaboticabal, SP

\begin{abstract}
RESUMO
O presente trabalho foi conduzido com o objetivo de avaliar a ausência e a inclusão de glicerina na dieta de cordeiros terminados em confinamento, sobre as características da carcaça e a qualidade da carne no músculo semimembranosus. Foram utilizados 40 cordeiros machos, não castrados, da raça $1 / 2$ Dorper 1/2 Santa Inês, desmamados com idade média de 90 dias e peso médio inicial de $21 \pm 2,3 \mathrm{~kg}$. Os tratamentos constituíram-se de duas dietas: G0 - ausência de glicerina e G10 - inclusão de 10\% de glicerina na MS. O delineamento experimental utilizado foi o inteiramente ao acaso, com dois tratamentos e 20 repetições. Observou-se efeito para peso de abate $(\mathrm{P}=0,041)$ e rendimento de carcaça fria $(\mathrm{P}=0,019)$ entre os tratamentos. Conclui-se que os cordeiros alimentados com a inclusão de glicerina (inclusão de $10 \%$ de glicerina na MS) apresentaram melhor rendimento de carcaça fria e menor peso de abate, sem que fossem alteradas as demais características estudadas.
\end{abstract}

Palavras-chave: carcaça, cordeiro, glicerina, qualidade da carne

\begin{abstract}
This study was conducted to evaluate absence and the inclusion of glycerin in the diet of feedlot finished lambs on carcass characteristics and meat quality in the semimembranosus muscle. Forty males of the breed $1 / 2$ Dorper $1 / 2$ Santa Inês weaned with average age of 90 days and average weight of $21+2.3 \mathrm{~kg}$ were included. The treatments consisted of two diets: G0 - absence of glycerin and G10 - inclusion of 10\% glycerol. The experimental design was completely randomized, with two treatments and 20 repetitions. There was effect to slaughter weight $(P=0.041)$ and cold carcass yield $(P=0.019)$ between treatments. We conclude that the lambs fed the inclusion of glycerin (10\%) showed better cold carcass yield and lower slaughter weight without changing the other characteristics studied.
\end{abstract}

Keywords: carcass, lamb, glycerin, meat quality

\section{INTRODUÇÃO}

$\mathrm{O}$ alto potencial produtivo dos ovinos e o crescente mercado consumidor por carne ovina de qualidade são fatores que estimulam a realização de pesquisas com essa categoria animal (Pires et al., 2000). Segundo Osório et al. (1998), com a intensificação da produção ovina, a sanidade, a alimentação, a reprodução do rebanho e as instalações necessitam de manejos adequados em cada fase de produção.

Recebido em 15 de abril de 2016

Aceito em 12 de abril de 2017

E-mail: elisadaurea@gmail.com
A terminação de cordeiros em confinamento com utilização de dietas de melhor qualidade diminui o tempo para os animais atingirem o peso ao abate. Permite, ainda, a produção de cordeiros precoces, com melhores atributos de carcaças e carne, agregando valores a esses produtos (Yamamoto, 2006).

A produção de carne é uma alternativa econômica para a ovinocultura em razão de sua excelência e qualidade. Entretanto, a fim de que o consumidor tenha boa aceitação em relação a esse produto, deve-se procurar gerar produtos que atendam às necessidades de mercado. Para 
que isso ocorra, torna-se necessária a produção de animais jovens (cordeiros), que apresentam carcaças com adequada quantidade de gordura e que apresentem bom rendimento. Isso porque o cordeiro é a categoria que oferece carne de maior aceitabilidade no mercado consumidor, com melhores características de carcaça e menor ciclo de produção.

Para ser eficiente nesse mercado cada vez mais competitivo, é necessário melhorar os sistemas de produção, fazendo com que a carne ovina apresente parâmetros de qualidade desejáveis, tanto quantitativos como qualitativos (Santos, 2002). Portanto, torna-se imprescindível a busca de alimentos alternativos, entre eles a glicerina, visando identificar as possíveis diferenças na qualidade da carcaça e da carne de cordeiros alimentados com essa fonte de energia.

Diante disso, o trabalho teve como objetivo avaliar a ausência e a inclusão de glicerina na dieta de cordeiros terminados em confinamento, sobre as características da carcaça e qualidade da carne no músculo semimembranosus.

\section{MATERIAL E MÉTODOS}

O experimento foi conduzido nas instalações da Unidade Animal de Estudos Digestivos e Metabólicos pertencente ao Departamento de Zootecnia da Faculdade de Ciências Agrárias e Veterinárias da Universidade Estadual Paulista, em Jaboticabal, São Paulo, de acordo com os princípios éticos na experimentação animal (protocolo $\mathrm{n}^{\circ}$ 020589/12) determinados pelo Conselho de Ética em Experimentação Animal da referida instituição.

Foram utilizados 40 cordeiros machos, não castrados, da raça $1 / 2$ Dorper $1 / 2$ Santa Inês, desmamados, com idade média de 90 dias e peso médio inicial de $21 \pm 2,3 \mathrm{~kg}$, os quais permaneceram alojados em baias individuais de confinamento, equipadas com comedouros e bebedouros. Obedeceu-se a um período de 14 dias para adaptações às dietas e instalações, e, após esse período, os animais foram confinados, em média, por 51 dias.

Duas dietas foram formuladas de modo a atender as exigências nutricionais de cordeiros de acordo com o NRC (Nutrient..., 2007). O volumoso foi constituído de feno de tifton moído, e o concentrado à base de milho em grão moído, farelo de soja, glicerina, calcário calcítico e mistura mineral.

As dietas foram denominadas G0 - ausência de glicerina e G10 - inclusão de $10 \%$ de glicerina na MS. A glicerina utilizada possuía $83 \%$ de glicerol, $95 \%$ de matéria seca e $6 \%$ de sais (dos quais $99 \%$ foram compostos por cloreto de sódio e $0,01 \%$ por metanol). As duas dietas foram avaliadas na relação volumoso e concentrado de 20:80 na matéria seca. A proporção dos ingredientes e a composição químicobromatológica das dietas encontram-se na Tab. 1.

A dieta foi fornecida duas vezes ao dia (oito e 16 horas), e a quantidade de alimento oferecida ajustada a cada três dias, com base no consumo observado do dia anterior, permitindo-se sobras de $10 \%$, caracterizando consumo ad libitum.

Ao final do período experimental, todos os animais foram abatidos e submetidos a jejum de dieta sólida por 16 horas. No músculo semimenbranosus (lado esquerdo), foram determinados o $\mathrm{pH}$ ( $\mathrm{pH}$ inicial) e a cor (cor inicial), com auxílio de um peagâmetro digital e do colorímetro Minolta Meter CR-400. A carcaça de cada animal foi dividida em duas meias-carcaças, pesadas para obter-se o peso e o rendimento de carcaça quente (PCQ) $\left(\mathrm{RQC}=(\mathrm{PCQ} / \mathrm{PCA})^{*} 100\right)$. As carcaças foram transferidas para câmara frigorífica a $4^{\circ} \mathrm{C}$ por 24 horas, e novamente mediu-se o $\mathrm{pH}$ ( $\mathrm{pH}$ final) e a cor (cor final) no mesmo músculo. Ao final desse período, as carcaças foram pesadas para obtenção do peso de carcaça fria (PCF), determinando-se, assim, o rendimento de carcaça fria $\left(\mathrm{RCF}=(\mathrm{PCF} / \mathrm{PCA})^{*} 100\right)$ e a perda de peso ao resfriamento (PPR=(PCQ-PCF/PCQ)*100), conforme a metodologia utilizada por Osório et al. (2012). Após os procedimentos anteriores, realizou-se um corte na carcaça esquerda entre a $12^{\mathrm{a}}$ e a $13^{\mathrm{a}}$ costela, para mensurações da área de olho de lombo e espessura de gordura subcutânea. Amostras do músculo semimembranosus foram retiradas da meiacarcaça esquerda, embaladas e resfriadas a $-20^{\circ} \mathrm{C}$ para posteriores determinações de força de cisalhamento, perdas por cocção, capacidade de retenção de água, índice de fragmentação miofibrilar, comprimento de sarcômero, colesterol total e perfil de ácidos graxos. 
Tabela 1. Porcentagem dos ingredientes e composição químico-bromatológica das dietas experimentais (\% MS)

\begin{tabular}{|c|c|c|}
\hline & \multicolumn{2}{|c|}{ Dietas } \\
\hline Ingredientes & $\mathrm{G}^{1}$ & $\mathrm{G} 10^{2}$ \\
\hline Feno de capim-tifton & 20,00 & 20,00 \\
\hline Milho em grão moído & 55,40 & 45,40 \\
\hline Glicerina & - & 10,00 \\
\hline Farelo de soja & 23,00 & 23,00 \\
\hline Calcário calcítico & 0,60 & 0,60 \\
\hline Mistura mineral $^{2}$ & 1,00 & 1,00 \\
\hline \multirow[t]{2}{*}{ Total } & 100 & 100 \\
\hline & \multicolumn{2}{|c|}{ Composição (\%MS) } \\
\hline Matéria seca & 89,47 & 88,83 \\
\hline Matéria mineral & 5,00 & 5,19 \\
\hline Matéria orgânica & 84,47 & 83,64 \\
\hline Extrato etéreo & 3,01 & 3,45 \\
\hline Proteína bruta & 19,09 & 18,71 \\
\hline FDNcp $^{3}$ & 28,16 & 26,15 \\
\hline $\mathrm{NDT}^{4}$ & 77,32 & 78,96 \\
\hline
\end{tabular}

${ }^{1} \mathrm{G} 0$ - dieta com ausência de glicerina; ${ }^{2} \mathrm{G} 10$ - dieta com a inclusão de $10 \%$ de glicerina.

${ }^{2}$ Mistura mineral comercial para ovinos $(\mathrm{P}=60 \mathrm{~g} ; \mathrm{Ca}=110 \mathrm{~g} ; \mathrm{Na}=195 \mathrm{~g} ; \mathrm{Cl}=300 \mathrm{~g} ; \mathrm{Mg}=10 \mathrm{~g} ; \mathrm{S}=25 \mathrm{mg} ; \mathrm{Zn}=4.000 \mathrm{mg}$; $\mathrm{Cu}=600 \mathrm{mg} ; \mathrm{Mn}=600 \mathrm{mg} ; \mathrm{Fe}=1.200 \mathrm{mg} ; \mathrm{Co}=100 \mathrm{mg} ; \mathrm{I}=180 \mathrm{mg} ; \mathrm{Se}=12 \mathrm{mg} ; \mathrm{Fl}$ (máximo)=0,60mg); ${ }^{3}$ fibra em detergente neutro corrigido para cinzas e proteína; ${ }^{4}$ nutrientes digestíveis totais.

Para as análises de perdas por cocção e força de cisalhamento, as amostras foram descongeladas a $4^{\circ} \mathrm{C}$ por 24 horas e cozidas em forno elétrico (Layr, Luxo Inox) pré aquecido a $150^{\circ} \mathrm{C}$. A temperatura interna foi monitorada por termômetro (20-gauge copper-constantan thermocouples, Omega Engineering, Stamford, CT) localizado aproximadamente no centro geométrico de cada bife, acoplado a um monitor digital. Quando a temperatura interna atingiu $35^{\circ} \mathrm{C}$, o bife foi virado e cozido até atingir temperatura interna de $70^{\circ} \mathrm{C}$. As amostras foram, então, resfriadas a $4^{\circ} \mathrm{C}$ por 24 horas (Research..., 1995). Oito amostras cilíndricas de $1,27 \mathrm{~cm}$ de diâmetro foram removidas de cada bife, paralelamente ao comprimento das fibras musculares (Research..., 1995). Cada amostra cilíndrica foi cortada ao centro, perpendicularmente à direção das fibras, por aparelho Warner-Bratzler (G-R Manufacturing Company, Manhattan, KS - USA). As perdas por cocção foram mensuradas nos mesmos bifes utilizados para avaliação de força de cisalhamento, por meio da diferença gravimétrica entre o bife antes e após o cozimento.

$\mathrm{Na}$ determinação da capacidade de retenção de água, foi utilizada a metodologia descrita por Hamm, citada por Cañeque e Sañudo (2005), na qual amostras de carne de 400mg foram colocadas, no sentido transversal das fibras, sobre papel-filtro, entre duas placas acrílicas e, sobre estas, foi colocado peso de $10 \mathrm{~kg}$ por cinco minutos. Posteriormente, as amostras foram pesadas, e, por diferença, calculou-se a quantidade de água perdida. $O$ resultado foi expresso em porcentagem de água exsudada em relação ao peso inicial da amostra.

O comprimento de sarcômero foi determinado pelo método de difração a laser (Cross et al., 1981) das fibras musculares obtidas de cubos de $1,0 \mathrm{~cm}$ cortados em duplicata de diferentes partes do músculo semimembranosus.

O índice de fragmentação miofibrilar da carne foi determinado de acordo com Culler et al. (1978). De cada amostra, ainda congelada, foram retiradas duas subamostras com $3 \mathrm{~g}$ cada, as quais foram picadas com bisturi, retirando-se qualquer tecido conectivo ou gordura aparente. As amostras foram, então, homogeneizadas no Turrax em três seções de 30 segundos cada, com $30 \mathrm{~mL}$ da solução de extração contendo $\mathrm{KCl}$ $100 \mathrm{mM}$, fosfato de potássio $20 \mathrm{mM}$, EDTA $1 \mathrm{mM}, \mathrm{MgCl} 21 \mathrm{mM}$ e azida sódica $1 \mathrm{mM}$. Em seguida, a solução homogeneizada foi centrifugada, por 15 minutos, a $15.000 \mathrm{rpm}$, a $4^{\circ} \mathrm{C}$. Após descartar o sobrenadante, o precipitado foi disperso com $30 \mathrm{~mL}$ da solução de 
extração, agitado com um bastão de vidro e centrifugado novamente. Essa operação foi repetida mais uma vez. Após descartar o sobrenadante, ao precipitado foram adicionados $10 \mathrm{~mL}$ da solução de extração e a suspensão obtida foi passada através de peneira de polietileno para remoção do tecido conectivo. $\mathrm{Na}$ suspensão de miofibrilas, foi determinada a concentração de proteína pelo método do biureto, descrito por Gornall et al. (1949). Uma alíquota da suspensão de miofibrilas foi diluída com a solução de extração até uma concentração proteica de $0,5 \pm 0,05 \mathrm{mg} / \mathrm{mL}$. A suspensão diluída de miofibrilas foi agitada e colocada na cubeta, sendo, logo em seguida, feita a leitura da densidade óptica a 540nm em espectrofotômetro. Para obtenção do índice de fragmentação miofibrilar, foi multiplicado o valor obtido de densidade óptica a 540nm por 200.

Para a determinação de colesterol total, foi utilizada a metodologia de Bohac et al. (1998), citados por Bragagnolo e Rodriguez-Amayala (1992), na qual 10 gramas de carne crua foram submetidos à extração de lipídeos com clorofórmico:metanol (2:1). Em seguida, $10 \mathrm{~mL}$ desse extrato clorofórmico foram submetidos à saponificação com hidróxido de potássio e etanol a $90 \%$, sendo a fração insaponificável extraída com hexano. A reação final foi realizada entre a fração insaponificável, ácida acética saturada com sulfato ferroso e ácido sulfúrico. Após 10 minutos de resfriamento, as amostras foram submetidas à leitura espectofotométrica a 490nm. $\mathrm{O}$ perfil de ácidos graxos foi analisado em cromatógrafo gasoso Shimadzu 14B, equipado com detector de ionização de chama e coluna capilar de sílica fundida. A identificação dos picos foi feita por comparação dos tempos de retenção com os de padrões de ésteres metílicos de ácidos graxos da Sigma.

O delineamento experimental utilizado foi inteiramente ao acaso, composto por 40 animais, dois tratamentos e 20 repetições. Os cálculos estatísticos foram realizados por meio dos procedimentos GLM do programa estatístico SAS na versão 9.0, e as médias foram comparadas pelo teste de Tukey a 5\% de probabilidade.

\section{RESULTADOS E DISCUSSÃO}

As interações entre os fatores não foram significativas $(\mathrm{P}>0,05)$ na maioria das situações, PCQ ( $\mathrm{P}=0,696)$, RCQ $(\mathrm{P}=0,068), \mathrm{PCF}(\mathrm{P}=0,285)$ e PPR ( $\mathrm{P}=0,183)$, apenas para PA e RCF, em que houve significância entre os tratamentos $(\mathrm{P}<0,05)$ (Tab. 2).

Tabela 2. Peso de abate, peso de carcaça quente, rendimento de carcaça quente, peso de carcaça fria, rendimento de carcaça fria, perda de peso por resfriamento, área de olho de lombo, espessura de gordura subcutânea, $\mathrm{pH}$ inicial e pH final de cordeiros terminados em confinamento, alimentados com a ausência e a presença de glicerina

\begin{tabular}{|c|c|c|c|c|}
\hline \multirow{2}{*}{ Variáveis } & \multicolumn{2}{|c|}{ Dietas $^{1}$} & \multirow{2}{*}{$\mathrm{EPM}^{2}$} & \multirow{2}{*}{ Valor $-\mathrm{p}^{3}$} \\
\hline & G0 & G10 & & \\
\hline PA (kg) & 34,08 & 33,30 & 1,391 & 0,041 \\
\hline PCQ (kg) & 16,04 & 16,13 & 0,587 & 0,696 \\
\hline $\operatorname{RCQ}(\%)$ & 47,09 & 48,46 & 4,989 & 0,068 \\
\hline $\mathrm{PCF}(\mathrm{kg})$ & 15,63 & 15,92 & 0,679 & 0,285 \\
\hline $\mathrm{RCF}(\%)$ & 45,91 & 47,83 & 6,150 & 0,019 \\
\hline $\operatorname{PPR}(\%)$ & 3,49 & 2,23 & 6,779 & 0,182 \\
\hline $\operatorname{AOL}\left(\mathrm{cm}^{2}\right)$ & 10,71 & 11,38 & 2,452 & 0,183 \\
\hline EGS (mm) & 1,60 & 1,78 & 0,127 & 0,104 \\
\hline $\mathrm{pH}$ inicial & 6,53 & 6,51 & 0,033 & 0,766 \\
\hline pH final & 5,75 & 5,75 & 0,016 & 0,839 \\
\hline
\end{tabular}

${ }^{1}$ G0 - dieta com ausência de glicerina; G10 - dieta com a inclusão de $10 \%$ de glicerina; ${ }^{2}$ erro-padrão da média; ${ }^{3}$ probabilidade. Médias nas linhas, em que $\mathrm{P}<0,05$, diferem entre si pelo teste de Tukey a $5 \%$.

Os PA e os RCF foram 34,08 e $33,30 \mathrm{~kg}$ $(\mathrm{P}=0,041)$ e 45,91 e $47,83 \% \quad(\mathrm{P}=0,019)$, respectivamente, para os tratamentos com a ausência e a inclusão de glicerina.
O trato gastrintestinal (TGI) cheio constitui a maior porcentagem em relação ao peso de abate, o que demonstra que é o fator de maior influência nos rendimentos de carcaça, além de 
outros fatores que podem influenciar o rendimento de carcaça, tais como, o grau de acabamento (a quantidade de gordura), o tipo da dieta (mudanças no tamanho dos órgãos), o sexo e a raça.

Nota-se que o tratamento com a inclusão de glicerina apresentou menor PA e maior RCF, em relação ao tratamento com ausência de glicerina, que exibiu maior PA e menor RCF (Tab. 2). Isso porque o peso de abate depende do estado de hidratação e do conteúdo do trato digestivo, e tais fatores podem ter influenciado a diferença entre a variável de PA dos tratamentos, visto que esses animais foram submetidos a jejum de dieta sólida por 16 horas, havendo uma diminuição do conteúdo ruminal.

A glicerina é um precursor de glicogênio, que é rapidamente fermentável no rúmen, apresentando, como principal característica, aumento na concentração de propionato. E à medida que aumenta o nível de propionato na dieta, há maior produção de energia (AGV). Esse AGV é absorvido no rúmen, atinge a corrente sanguínea e é levado ao fígado, onde é transformado em glicose, o que pode ter proporcionado maior aporte de glicose para a deposição muscular, o que explicaria esse aumento de RCF, obtendo-se, assim, um melhor desenvolvimento de carcaça.

Os valores encontrados para AOL dos tratamentos foram 10,71 e $11,38 \mathrm{~cm}^{2}(\mathrm{P}=0,183)$, respectivamente (Tab. 2). A AOL aumenta em conseqüência do maior peso e idade de abate, por ser uma medida objetiva e apresentar utilidade na predição da quantidade de músculo na carcaça.

$\mathrm{O}$ tratamento com ausência de glicerina apresentou menor AOL $\left(10,71 \mathrm{~cm}^{2}\right)$ em relação ao tratamento com a inclusão de glicerina $\left(11,38 \mathrm{~cm}^{2}\right)$, embora estatisticamente eles não tenham sido diferentes $(\mathrm{P}>0,05)$. Gunn et al. (2010), ao trabalharem com níveis crescentes de glicerina $(0,5,10,15$ e $20 \%)$ na dieta de cordeiros, não encontraram diferenças para a medida de AOL.

Não foram detectadas diferenças significativas $(\mathrm{P}>0,05)$ para EGS, que apresentaram os valores 1,60 e $1,78 \mathrm{~mm}(\mathrm{P}=0,104)$, respectivamente. Esse resultado é desejável, visto que a gordura é um importante elemento de proteção da carcaça contra os efeitos adversos do frio, protegendo-a dos efeitos negativos da baixa temperatura do resfriamento e do congelamento, bem como da perda excessiva de água pela formação de cristais de gelo dentro das células (Rodrigues et al., 2006). Nesse contexto, se a cobertura de gordura não for em excesso, maior que $3 \mathrm{~mm}$ em cordeiros, isso contribui positivamente para a qualidade da carcaça.

O pH é uma variável muito importante, pois está relacionado com a qualidade da carne. Em condições normais, ocorre a redução do $\mathrm{pH}$, que está em torno de 7,0 no animal vivo, e, após 24 horas do abate, em torno de 5,4 a 5,7. Essa redução é o resultado da utilização das reservas de glicogênio via glicólise, que tem, como produto final, o ácido lático. Sob condições anormais, como estresse pré-abate, essa queda pode ser acelerada nas primeiras horas após o abate, ou o $\mathrm{pH}$ pode não abaixar e ficar em torno de 6,0 após as 24 horas, ocorrendo, assim, anomalias na carne (carne PSE (pálida, mole e exudativa) ou DFD (dura, firme e seca). A carne PSE é mais comum em suínos, sendo incomum em ruminantes.

Neste estudo, o pH final médio das carcaças dos cordeiros encontrou-se no limite estabelecido $(5,4$ a 5,7) para o início do aparecimento de carnes DFD (dura, firme e seca) (Tab. 2). Além disso, animais não castrados são susceptíveis a apresentarem carne DFD, devido provavelmente à insuficiente cobertura de gordura. No caso dos cordeiros, a baixa espessura de gordura pode influenciar diretamente o seu resfriamento e os processos post mortem, fato que não foi evidenciado nos animais em questão.

A cor da carne não foi influenciada $(\mathrm{P}>0,05)$ pelos tratamentos (Tab. 3). Em ovinos são descritos valores médios de 30,03 a 49,47 para $\mathrm{L}^{*}, 8,24$ a 23,53 para a* e 3,38 a 11,10 para $\mathrm{b}^{*}$ (Sañudo et al., 2000). Neste estudo, por tratar-se de animais jovens, mantidos em áreas relativamente pequenas (ausência de exercícios prolongados), e por receberem dieta à base de alimentos energéticos, não houve alteração na coloração da carne. 
Tabela 3. Coloração da carne de cordeiros terminados em confinamento alimentados com a ausência e a presença de glicerina

\begin{tabular}{ccccc} 
Características $_{2}$ & \multicolumn{2}{c}{ Dietas $^{1}$} & \multirow{2}{*}{ EPM $^{2}$} & Valor $-\mathrm{p}^{3}$ \\
\cline { 2 - 3 } Inicial & G0 & G10 & & \\
L $^{*}$ & 36,38 & 34,37 & 3,898 & 0,396 \\
$\mathrm{a}^{*}$ & 15,17 & 15,44 & 3,550 & 0,659 \\
$\mathrm{~b}^{*}$ & 3,55 & 3,78 & 0,677 & 0,375 \\
Final & & & & \\
$\mathrm{L}^{*}$ & 36,35 & 35,99 & 4,943 & 0,608 \\
$\mathrm{a}^{*}$ & 16,89 & 17,29 & 5,931 & 0,609 \\
$\mathrm{~b}^{*}$ & 7,63 & 6,68 & 5,946 & 0,371 \\
\hline
\end{tabular}

${ }^{1}$ G0 - dieta com ausência de glicerina; G10 - dieta com a inclusão de $10 \%$ de glicerina; ${ }^{2}$ erro-padrão da média; ${ }^{3}$ probabilidade. Médias nas linhas não diferem entre si pelo teste de Tukey $(\mathrm{P}>0,05)$.

Não foram constatadas diferenças significativas $(\mathrm{P}>0,05)$ entre os tratamentos para as variáveis de FC $(\mathrm{P}=0,094), \quad \mathrm{PPC} \quad(\mathrm{P}=0,655), \quad \mathrm{CRA}$ $(\mathrm{P}=0,472)$, MFI $(\mathrm{P}=0,520)$ e $\mathrm{CS}(\mathrm{P}=0,487)$ e colesterol total $(\mathrm{P}=0,484)$, cujos valores médios foram de $55,45 \%, 37,07 \%, 3,25 \mathrm{~kg} / \mathrm{cm}^{2}, 75,23$, $1,18 \mu \mathrm{m}$ e $31,69 \mathrm{mg} / 100 \mathrm{~g}$, respectivamente (Tab. 4).

Os valores médios encontrados no presente estudo para FC e PPC $\left(3,25 \mathrm{~kg} / \mathrm{cm}^{2}\right.$ e $\left.37,07 \%\right)$ foram inferiores aos relatados por Gomes et al. (2011). Isso porque os atributos qualitativos da carne apresentam grandes variações, principalmente entre o genótipo, que influencia, entre outras características, a capacidade de retenção de água, as perdas por cocção, a cor e a dureza, e, com relação ao peso do animal, este interfere no grau de gordura, na conformação e na idade do animal. Vale ressaltar que foram estabelecidos entre os autores diferentes pesos de abate e animais (cruzamento). De acordo com Bickerstaffe et al. (1997), carne de cordeiros que apresentem força de cisalhamento acima de $5 \mathrm{~kg}$ é definida como dura e tem a aceitação reduzida pelos consumidores. No presente trabalho, a média obtida para força de cisalhamento está dentro da faixa de aceitação, considerada uma carne macia.

Tabela 4. Força de cisalhamento (FC), perdas de peso por cocção (PC), capacidade de retenção de água (CRA), índice de fragmentação miofibrilar (IFM), comprimento de sarcômero (CS) e colesterol do músculo semimembranosus de cordeiros terminados em confinamento, alimentados com a ausência e a presença de glicerina

\begin{tabular}{|c|c|c|c|c|}
\hline \multirow{2}{*}{ Características } & \multicolumn{2}{|c|}{ Dietas $^{1}$} & \multirow{2}{*}{$\mathrm{EPM}^{2}$} & \multirow{2}{*}{ Valor $-\mathrm{p}^{3}$} \\
\hline & G0 & G10 & & \\
\hline $\mathrm{FC}\left(\mathrm{kg} / \mathrm{cm}^{2}\right)$ & 3,50 & 3,01 & 0,799 & 0,094 \\
\hline PPC (\%) & 37,37 & 36,77 & 7,161 & 0,655 \\
\hline CRA $(\%)$ & 55,01 & 55,90 & 5,107 & 0,472 \\
\hline MFI & 74,11 & 76,36 & 6,850 & 0,520 \\
\hline $\mathrm{CS}(\mu \mathrm{m})$ & 1,18 & 1,18 & 0,001 & 0,487 \\
\hline Colesterol (mg/100g) & 32,40 & 30,98 & 3,854 & 0,484 \\
\hline
\end{tabular}

${ }^{1}$ G0 - dieta com ausência de glicerina; G10 - dieta com a inclusão de $10 \%$ de glicerina; ${ }^{2}$ erro-padrão da média; ${ }^{3}$ probabilidade. Médias nas linhas não diferem entre si pelo teste de Tukey $(\mathrm{P}>0,05)$.

A ausência e a inclusão de glicerina na dieta não influenciaram o IFM e o CS, indicando uma carne com resultados satisfatórios a essas variáveis. Segundo Culler et al. (1978), valores do índice de fragmentação de 60 ou acima de 60 denotam uma carne muito macia; valores de 50, uma carne macia; e valores abaixo de 50, uma carne pouco macia. As médias encontradas entre os tratamentos $(75,23)$ caracterizam uma carne muito macia, porém o IFM é eficaz em detectar a proteólise enzimática, não tendo habilidade em identificar variações devido a outras características.

O teor de colesterol do presente estudo $(31,69 \mathrm{mg} / 100 \mathrm{~g})$ foi inferior ao encontrado por 
Madruga et al. (2005), que verificaram médias que variaram de 44,10 a 57,80 mg/100 de colesterol na carne de cordeiros da raça Santa Inês terminados com diferentes dietas. Vale ressaltar que animais abatidos com menores pesos apresentam teores de colesterol mais baixos quanto à menor quantidade de gordura relacionada à carcaça. Além disso, a variação da concentração de colesterol pode estar relacionada à metodologia empregada, aos tipos de músculos analisados, à alimentação, tal como, a idade ao abate e o sexo do animal (Bragagnolo e Rodriguez-Amayala, 1992).

Vários fatores podem afetar o processo de biohidrogenação e a composição dos ácidos graxos depositados na carne. Dentre eles, destacam-se o sistema de alimentação, a composição das dietas, a relação volumoso:concentrado e o tipo de volumoso utilizado (Demirel et al., 2006; Nuernberg et al., 2008).

Estudos têm demonstrado que o glicerol inibe a lipólise ruminal dos ácidos graxos (Krueger et al., 2010; Edwards et al., 2012), o que pode aumentar a passagem de intermediários da biohidrogenação para o duodeno e a agregação em produtos cárneos. Assim, esses resultados poderão contribuir para a produção de carne ovina (aspectos qualitativos), auxiliando na geração de um produto que atenda à demanda do mercado consumidor, principalmente relacionado às proporções de músculo e gordura e ao teor de colesterol das carcaças de cordeiros terminados em confinamento (Arruda et al., 2012).

Não houve influência $(\mathrm{P}>0,05)$ dos tratamentos sobre os ácidos graxos encontrados (Tab. 5). Os ácidos graxos em maiores concentrações foram o mirístico $(2,42 \mathrm{~g} / 100 \mathrm{~g}$ de gordura), o palmítico $(23,95 \mathrm{~g} / 100 \mathrm{~g}$ de gordura), o esteárico $(13,58 \mathrm{~g} / 100 \mathrm{~g}$ de gordura), o palmitoleico $(2,56 \mathrm{~g} / 100 \mathrm{~g}$ de gordura), o oleico $(45,94 \mathrm{~g} / 100 \mathrm{~g}$ de gordura) e o linoleico $(3,49 \mathrm{~g} / 100 \mathrm{~g}$ de gordura), constituindo $91,94 \%$ do total de ácidos graxos da carne dos cordeiros. Essas maiores concentrações também foram encontradas por Zapata et al.(2001), Gallo et al. (2007), Nuernberg et al. (2008), ao avaliarem diferentes dietas sobre o efeito de ácidos graxos na carne de cordeiros

Os ácidos graxos mais encontrados na carne ovina são o mirístico, o palmítico e o esteárico. Dos ácidos graxos saturados (AGS) frequentemente presentes na carne de ruminantes, os ácidos mirístico e palmítico apresentam alto potencial hipercolesterolêmico (Daley et al., 2010), sendo o mirístico de maior potencial (Scollan et al., 2006), porém de menor concentração comparado ao palmítico. Entretanto, a composição dos ácidos graxos pode sofrer variações em função do sexo, da raça e da dieta fornecida.

No entanto, apesar de os tratamentos não apresentarem diferenças $(\mathrm{P}>0,05)$ nas proporções de ácido oleico $(\mathrm{P}=0,504)$, o tratamento com a inclusão de glicerina $(46,36 \mathrm{~g} / 100 \mathrm{~g}$ de gordura) apresentou maior concentração em relação ao tratamento com ausência de glicerina $(45,53 \mathrm{~g} / 100 \mathrm{~g}$ de gordura) (Tab. 5). Entre os benefícios do ácido oleico, está o de melhorar o perfil das gorduras no sangue, no sentido de abaixar o colesterol ruim (LDL) e aumentar o bom (HDL).

Em relação ao ácido linoleico conjugado (CLA), não houve efeito $(\mathrm{P}>0,05)$ entre os tratamentos $(\mathrm{P}=0,321)$. O CLA é sintetizado no rúmen como um intermediário do processo de biohidrogenação do ácido linoleico. Ressalte-se que os ácidos graxos insaturados aumentam o potencial de oxidação, influenciando diretamente a vida de prateleira do produto (Banskalieva et al., 2000). O ácido linoleico conjugado (CLA) é um ácido graxo encontrado apenas em produtos animais e em maior quantidade nos produtos de ruminantes.

$\mathrm{O}$ ácido graxo cáprico $(\mathrm{P}=0,078)$ teve uma tendência a ser significativo entre os tratamentos (Tab. 5). O ácido cáprico, também conhecido como ácido decanoico, é sintetizado de células da pele de ruminantes, sendo responsável pelo odor característico da espécie. O tratamento com a inclusão de glicerina pode ter alterado a concentração desse AGS na carne. 
Tabela 5. Perfil de ácidos graxos $(\mathrm{g} / 100 \mathrm{~g}$ de gordura) de cordeiros terminados em confinamento, alimentados com a ausência e a presença de glicerina

\begin{tabular}{|c|c|c|c|c|c|}
\hline \multirow{2}{*}{\multicolumn{2}{|c|}{ Ácidos graxos saturados (AGS) }} & \multicolumn{2}{|c|}{$\operatorname{Dietas}^{1}$} & \multirow[t]{2}{*}{$\mathrm{EPM}^{2}$} & \multirow[t]{2}{*}{ Valor de $\mathrm{p}^{3}$} \\
\hline & & G0 & G10 & & \\
\hline Cáprico & C10:0 & 0,13 & 0,11 & 0,007 & 0,077 \\
\hline Laúrico & $\mathrm{C} 12: 0$ & 0,10 & 0,09 & 0,003 & 0,575 \\
\hline Mirístico & C14:0 & 2,51 & 2,34 & 0,218 & 0,263 \\
\hline Pentadecanoico & C15:0 & 0,53 & 0,52 & 0,022 & 0,171 \\
\hline Palmítico & C16:0 & 24,04 & 23,85 & 0,020 & 0,817 \\
\hline Heptadecanoico & $\mathrm{C} 17: 0$ & 1,35 & 1,46 & 1,525 & 0,594 \\
\hline Esteárico & C18:0 & 13,71 & 13,46 & 0,168 & 0,619 \\
\hline Araquídico & C 20:0 & 0,07 & 0,06 & 0,080 & 0,211 \\
\hline \multicolumn{6}{|c|}{ Ácidos graxos insaturados (AGI) } \\
\hline Miristoleico & C14:1 & 0,40 & 0,34 & 0,160 & 0,244 \\
\hline Palmitoleico & C16:1 & 2,60 & 2,53 & 3,325 & 0,676 \\
\hline Heptadecenoico & C $17: 1$ & 1,41 & 1,56 & 4,825 & 0,238 \\
\hline Cis-vacênico & $\mathrm{C} 18: 1 \omega-7$ & 2,08 & 2,06 & 0,004 & 0,672 \\
\hline Oleico & $\mathrm{C} 18: 1 \omega-9$ & 45,53 & 46,36 & 0,864 & 0,504 \\
\hline Linoleico & C18:2 $\omega-6$ & 3,59 & 3,39 & 0,003 & 0,199 \\
\hline$\alpha$ linolênico & $\mathrm{C} 18: 3 \omega-3$ & 0,14 & 0,16 & 0,003 & 0,446 \\
\hline$\gamma$ linolênico & $\mathrm{C} 18: 3 \omega-6$ & 0,04 & 0,05 & 0,015 & 0,111 \\
\hline Linoleico conjugado (CLA) & $\mathrm{C} 18: 2 \mathrm{c} 9, \mathrm{t} 11$ & 0,52 & 0,46 & 0,001 & 0,321 \\
\hline Eicosenoico & C20:1 $\omega-9$ & 0,16 & 0,15 & 0,003 & 0,609 \\
\hline Eicosadienoico & $\mathrm{C} 20: 2$ & 0,03 & 0,03 & 0,000 & 0,871 \\
\hline $\begin{array}{l}\text { Eicosatrienoico (cis - 8, 11, } \\
\text { 14) }\end{array}$ & $\mathrm{C} 20: 3 \omega-6$ & 0,07 & 0,07 & 0,001 & 0,896 \\
\hline Araquidônico & $\mathrm{C} 20: 4 \omega-6$ & 0,56 & 0,59 & 0,170 & 0,843 \\
\hline Eicosapentaenoico (EPA) & $\mathrm{C} 20: 5 \omega-3$ & 0,02 & 0,03 & 0,001 & 0,202 \\
\hline Docosatetraenoico (DTA) & $\mathrm{C} 22: 4 \omega-6$ & 0,05 & 0,04 & 0,001 & 0,622 \\
\hline Docosa-hexaenoico (DHA) & $\mathrm{C} 22: 6 \omega-3$ & 0,01 & 0,01 & 0,001 & 0,882 \\
\hline Nervônico & $\mathrm{C} 24: 1 \omega-9$ & 0,07 & 0,07 & 0,001 & 0,853 \\
\hline
\end{tabular}

${ }^{\mathrm{I}} \mathrm{G} 0$ - dieta com ausência de glicerina; G10 - dieta com a inclusão de $10 \%$ de glicerina; ${ }^{2}$ erro-padrão da média; ${ }^{3}$ probabilidade. Médias nas linhas não diferem entre si pelo teste de Tukey $(\mathrm{P}>0,05)$.

\section{CONCLUSÃO}

A inclusão de $10 \%$ de glicerina na dieta de cordeiros terminados em confinamento não promove efeitos negativos nas características da carcaça e na qualidade da carne.

\section{AGRADECIMENTOS}

À Fundação de Amparo à Pesquisa do Estado de São Paulo (Fapesp), por financiar esta pesquisa, e à Caramuru Alimentos SA, pela doação da glicerina.

\section{REFERENCIAS}

ARRUDA, P.C.L.; PERREIRA, E.S.; PIMENTEL, P.G. et al. Perfil de ácidos graxos no Longissimus dorsi de cordeiros Santa Inês alimentados com diferentes níveis energéticos. Semin. Cienc. Agrar., v.33, p.1229-1240, 2012.

BANSKALIEVA, V.; SAHLU, T.; GOETSCH, A.L. Fatty acid composition of goat muscles and fat depots: a review. Small Rumin. Research, v.37, p.255-268, 2000.

BICKERSTAFFE, R.; Le COUTEUR, C.E.; MORTON, J.D. Consistency of tenderness in New Zealand retail meat. INTERNATIONAL CONGRESS OF MEAT SCIENCE AND TECHNOLOGY, 43., 1997, Auckland. Proceedings... Auckland, New Zealan: [s.n.], 1997. p.196-197. 
BOHAC, C.E.; RHEE, K.S.; CROSS, H.R. et al. Assessment of methodologies for colorimetric cholesterol assay of meats. J. Food. Sci., v.53, p.1642$1645,1988$.

BRAGAGNOLO, N.; RODRIGUEZ-AMAYA, D.B. Teores de colesterol em carne de frango. Rev. Farm. Bioquim., v.28, p.122-131, 1992.

CAÑEQUE, V.; SAÑUDO, C. Estandarización de las metodologías para evaluar la calidad del producto (animal vivo, canal, carne y grasa) en los rumiantes. Inst. Nac. Invest. Tecnol. Agrar. Aliment., v.3, p.455, 2005.

CROSS, H.R.; WEST, R.L.; DUTSON, T.R Comparison of methods for measuring sarcomere length in beef semitendinosus muscle. Meat Sci., v.5, p.261-266, 1981.

CULLER, R.D.; PARRISH, F.C.; SMITH, G.C.; CROSS, H.R. Relationship of myofibril fragmentation index to certain chemical, physical and sensory characteristics of bovine longissimus muscle. J. Food Sci., v.43, p.1177-1180, 1978.

DALEY, C.A.; ABBOTT, A.; DOYLE, P.S. et. al. A review of fatty acid profiles and antioxidant content in grass-fed and grain-fed beef. Nutr. J., v.10, p.9-10, 2010.

EDWARDS, H.D.; ANDERSON, R.C.; MILLER, R. $\mathrm{K}$. et al. Glycerol inhibition of ruminal lipolysis in vitro. J. Dairy Sci., v.95, p.5176-5181, 2012.

GALLO, S.B.; SIQUEIRA, E.R.; ROSA, G.B. Efeito da nutrição da ovelha e do cordeiro sobre o perfil de ácidos graxos do músculo Triceps brachii de cordeiros. Rev. Bras. Zootec., v.36, p.2069-2073, 2007.

GOMES, M.A.B.; MORAES, G.V.; MATAVELI, M. et al. Performance and carcass characteristics of lambs fed on diets supplemented with glycerin from biodiesel production. Rev. Bras. Zootec., v.40, p.22112219, 2011.

GORNALL, A.G.; BARDAWILL, C.J.; DAVID, M.M. Determination of serum proteins by means of the biuret reaction. J. Biol. Chem., v.177, p.751-766, 1949.

GUNN, P.J.; NEARY, M.K.; LEMENAGER, R.P. et al. Effects of crude glycerin on performance and carcass characteristics of finishing wether lambs. $J$. Anim. Sci., v.88, p.1771-1776, 2010.

KRUEGER, N.A.; ANDERSON, R.C.; TEDESCHI, T.R. et al. Evaluation of feeding glycerol on free-fatty acid production and fermentation kinetics of mixed ruminal microbes in vitro. Bioresour. Tech., v.101, p.8469-8472, 2010.
MADRUGA, M.S.; SOUSA, W.H.; ROSALES, M.D. et al. Qualidade da carne de cordeiros Santa Inês terminados em diferentes dietas. Rev. Bras. Zootec., v.34, p.309-315, 2005.

NUERNBERG, K.; FISCHER, A.; NUERNBERG, G.; ENDER, K.; DANNERBERG, D. Meat quality and fatty acid composition of lipids in muscle and fatty tissue of Skudde lambs fed grass versus concentrate. Small Ruminant Res., v.74, p.279-283, 2008.

NUTRIENT requirements of small ruminants: sheep, goats, cervids, and new world camelids. Washington: National Academy Press, 2007.

OSÓRIO J.C.S.; OSÓRIO, M.T.M.; VARGAS JUNIOR, F.M. et al. Critérios para abate do animal e a qualidade da carne. Rev. Agrar., v.5, p.433-443, 2012.

OSÓRIO, J.C.S.; ASTIZ, C.S.; OSÓRIO, M.T.M. Produção de carne ovina: alternativa para o Rio Grande do Sul. Pelotas: UFPEL, v.1, p.166, 1998.

RESEARCH guidelines for cookery, sensory evaluation and tenderness measurements of fresh meat. Chicago: AMSA / National Livestock and Meat Board, IL, 1995.

RODRIGUES, S.; CADAVEZ, V.; TEIXEIRA, A. Breed and maturity effects on Churra Galega Bragançana and Suffolk lamb carcass characteristics: killing-out proportion and composition. Meat Sci., v.72, p.288-293, 2006.

SAÑUDO, C.; ENSER, M.E.; CAMPO, M.M. et al. Fatty acid composition and sensory characteristics of lamb carcasses from Britain and Spain. Meat Sci., v.54, p.339-346, 2000.

SANTOS, C.L. Sistemas de cortes de cordeiros. In: SIMPÓSIO MINEIRO DE OVINOCULTURA, 2., 2002, Lavras. Anais... Lavras: UFLA, 2002. p.187206.

SCOLLAN, N.; HOCQETTE, J.F.; NUERNBERG, K. et al. Innovations in beef production systems that enhance the nutritional and health value of beef lipids and their relationship with meat quality. Meat Sci., v.74, p.17-33, 2006.

PIRES, C.C; SILVA, L.F; SCHLICK, F.E et al. Cria e terminação de cordeiros confinados. Cienc. Rural, v.30, p.875-880, 2000.

YAMAMOTO, S.M. Desempenho e características da carcaça e da carne de cordeiros terminados em confinamento com dietas contendo silagens de resíduos de peixes. 2006. 106f. Tese (Doutorado) Faculdade de Ciências Agrárias e Veterinárias, Universidade Estadual Paulista, Jaboticabal.

ZAPATA, J.F.F.; NOGUEIRA C.M.; SEABRA, L.M.J. et al. Composições centesimal e lipídica da carne de ovinos do nordeste brasileiro. Cienc. Rural, v.31, p.691-695, 2001. 